\title{
Toscana Virus Epidemiology: From Italy to Beyond
}

\author{
Maria G. Cusi ${ }^{*}{ }^{1}$, Gianni G. Savellini ${ }^{1}$ and Giacomo Zanelli ${ }^{2}$ \\ Department of Molecular Biology, ${ }^{I}$ Microbiology Section, ${ }^{2}$ Infectious Diseases Section, University of Siena, Policlinico \\ "S. Maria alle Scotte", Siena, Italy
}

\begin{abstract}
Toscana virus (TOSV) is an arthropod-borne virus which is transmitted to humans by Phlebotomus spp sandflies. Infection is the cause of brain injuries, such as aseptic meningitis and meningoencephalitis, in Italy mainly during the summer. More recently some unusual clinical manifestations due to TOSV with severe sequelae, such as ischemic complications and hydrocephalus, have been reported. TOSV represents an important emerging pathogen and its presence is being investigated in several European countries on the Mediterranean basin, including Italy, France, Spain, Portugal and Cyprus. Phylogenetic analysis has distinguished two genotypes of TOSV, A and B; the first is circulating mainly in Italy and the second in Spain, indicating a different geographic distribution possibly related to the vector. This distribution, evolving with the climate, globalization and habitat modification, has implications for the epidemiology of TOSV.
\end{abstract}

Keywords: Toscana virus, phleboviruses, vectors, epidemiology, meningitis.

\section{INTRODUCTION}

Toscana Virus (TOSV) belongs to the Phlebovirus genus of the Bunyaviridae family, it is an arthropod-borne virus transmitted to humans by Phlebotomus, Sergentomyia and Lutzomya genera, in particular by Phlebotomus perniciosus and $P$. perfiliewi. The virus can be transmitted transovarially in the insect vectors, but its animal reservoir has not been identified yet. TOSV isolation from the brain of a bat (Pipistrellus kuhli) has been the only evidence of the possible involvement of this species in the ecology of the virus [1-3]. However, serological investigations have shown that anti-TOSV specific IgG has been detected in some animal species [4], indicating that this virus can also infect animals [4]. Its genome is composed of three negative single-strand RNA segments (ssRNA -) designated Large (L), Medium (M) and Small (S). The different segments code respectively for the RNA-dependent RNA-polymerase (L) [5], two envelope glycoproteins $\left(\mathrm{G}_{\mathrm{N}}\right.$ and $\left.\mathrm{G}_{\mathrm{C}}\right)[6,7]$ and a nucleocapsid protein $(\mathrm{N})$ [8]. Moreover, two non-structural proteins (NSm and NSs) are coded by the M and S segments, respectively. Among sandfly-transmitted viruses, three serotypes have been identified: Naples, Sicilian and Toscana. Naples and Sicilian serotypes have the widest geographical distribution which is related to the distribution of the vector (P. pappatasi) and they have been isolated from sandflies in Africa, central Asia, the Americas and Europe. In temperate regions, peak sandfly activity occurs during summer when the human population in these areas is exposed to sand-fly transmitted diseases, including those caused by phleboviruses, as demonstrated by serological investigations performed on the indigenous populations and tourists visiting these areas [9-18]. SSFV and SNFV are aetiologic agents of mild, self-limited disease characterized by fever,

*Address correspondence to this author at the Department of Molecular Biology, Microbiology Section, University of Siena, Viale Bracci 1, 53100, Siena, Italy; Tel: +39 0577 233871; Fax: +39 0577 233870;

E-mail: cusi@unisi.it myalgia, and headache $[19,20]$. However, TOSV is the major cause of aseptic meningitis (95\%) and meningoencephalitis $(4.5 \%)$ and influenza-like illness during the summer season [21,22]. Most cases of the disease have been reported in residents or travelers in central Italy or Spain, but a growing number of cases has been recorded in other countries in the Mediterranean basin, including Portugal, France, Cyprus, Turkey and Greece [23-27]. Asymptomatic infection and infection without central nervous system involvement due to TOSV, such as febrile erythema or influenza-like illness, have also been described [21, 28]. Unusual clinical manifestations or severe sequelae, such as hydrocephalus, epididimo-orchitis and ischemic complications, have recently been reported [21, 22, 28-30]. Genome sequence information is now available for evaluating its geographical distribution, virus surveillance and studying emerging pathogens [10]. In the past few years, some scientific studies have focused on the genetic analysis and phylogenetic relationship between the TOSV strains that have been isolated in different European countries [31-34]. Two different clusters of TOSV, genotypes A and B, were clearly distinguished and the geographic distribution may be different for each TOS virus genotype [31]. Reinfection cases have not been detected so far and preexisting immunity plays a role in limiting disease in the affected areas of current TOSV prevalence. However, this virus could be a threat to human health, in particular for populations outside the considered area, thus research and surveillance studies should be promoted to prevent its spread in new areas.

\section{TOSCANA VIRUS IN ITALY}

Toscana virus was isolated for the first time in 1971 from P. perniciosus in Monte Argentario (Grosseto, Tuscany) [1, $35,36]$, but it was recognized as a causative agent of neurological disease in humans only in 1983, when it was isolated for the first time from a young woman with lymphocytic meningitis [37]. A serosurvey for the presence of antibodies to Sicilian sandfly virus, Naples sandfly virus and Toscana virus highlighted that in spite of the use of 
insecticide-spraying malaria eradication campaigns in Italy after 1940, Toscana virus was still observed annually in central Italy during summer, causing meningitis or meningoencephalitis $[19,20,38,39]$. The rate of TOSVassociated meningitis during summer in Italy was demonstrated by an epidemiological study conducted on hospitalized patients residing in Tuscany during the 19951998 period. About eighty percent of cases of aseptic meningitis were due to TOSV infection [38]. The incisive role of TOSV as an etiologic agent of neurological diseases in central Italy was clearly underlined by Pauri P. in a study conducted from 1999 through 2003 (personal communication). Further serological analyses were conducted on a high-risk population occupationally exposed to viral infection in two regions of Italy: Tuscany and Piedmont. The results indicated a TOSV seroprevalence of $77.2 \%$ in forestry workers, particularly in Tuscany, compared to $22.7 \%$ of seropositivity in the urban population (Table 1). This finding is strictly correlated with the favorable habitat for the arthropod vectors in the regions where the specific vector lives [40]. Moreover, this serological analysis underlined the presence of asymptomatic infections of TOSV in exposed people. Another serological investigation

Table 1. Prevalence of TOSV Antibodies in Occupationally Exposed and Citizens of Two Italian Regions [40]

\begin{tabular}{|c|c|c|c|}
\hline \multirow{2}{*}{ Population } & \multicolumn{3}{|c|}{ No. (\%) Tested for TOSV Antibodies } \\
\cline { 2 - 4 } & Positive & Negative & Total \\
\hline \hline \multicolumn{4}{|c|}{ Tuscany } \\
\hline Forestry workers & $278(77.2)$ & $82(22.8)$ & 360 \\
Control & $66(22.7)$ & $224(77.3)$ & 290 \\
\hline \multicolumn{4}{|c|}{ Piedmont } \\
\hline Forestry workers & $3^{\text {a }}(6)$ & $47(94)$ & 50 \\
Control & $1(2.5)$ & $39(97.5)$ & 40 \\
\hline
\end{tabular}

carried out on asymptomatic household contacts of central nervous system infection patients showed anti-TOS IgG seropositivity in $22 \%$ and $\mathrm{IgG} / \mathrm{IgM}$ seropositivity in $6 \%$ of the subjects [20,41]. These data confirm that TOSV infection can occur in humans with mild or even no symptoms. A more recent and wider study carried out in the Siena area during the years of 1993-2008 showed that a high rate of meningitis in the summer is due to TOSV infection (399 cases), with a peak in 2005 and 2006 (Fig. 1A) [42]. A significant decrease in cases was recorded in 2007-2008. A retrospective analysis of the climate in this area, during the summer of 2006 , revealed that the temperature was $3-5{ }^{\circ} \mathrm{C}$ higher than 2007, with more days at extremely higher temperatures compared to the seasonal mean values. The incidence of TOSV aseptic meningitis in central Italy was higher in July, August and September (Fig. 1B). Some sporadic TOSV activity was noted during the remaining span of time. Other reports of TOSV infections have been described in northern Italy (Emilia Romagna, Piedmont) [28, $40,43]$ and in other regions, including the Marches, Umbria, Lazio, Campania and Sardinia [44-46]. In this context, two cases of meningoencephalitis with severe sequelae, such as hydrocephalus caused by TOSV, were observed in Umbria [29]. A recent retrospective study on the antibody prevalence rates of Toscana virus (TOSV) among children and adults was performed in a population $(\mathrm{n}=2737)$ living in Tuscany during 1999-2006 [47]. The seroprevalence rate was $19.8 \%$ in adults and $5.8 \%$ in children, showing an age-dependent increase in TOSV specific immunity. Moreover, correlating seroprevalence to the clinical profile, the study indicated that asymptomatic TOSV infection is more frequent in young people $(91 \%)$ than in adults $(31.4 \%)$, in whom a higher incidence of severe signs of neurological disorders correlated to TOSV infection are present (Fig. 2). It is still unclear why this occurs.

\section{TOSCANA VIRUS IN THE IBERIAN PENINSULA}

Several clinical manifestations of TOSV infection have also been reported in Spain and Portugal. In Portugal, a retrospective study performed on cerebrospinal fluid samples from patients with a diagnosis of meningitis collected between May and September from 2002 through 2005 revealed the presence of TOSV in $5.6 \%$ patients, as a causative agent of neurological disease in Portuguese inhabitants [24]. A large epidemiological study conducted in the province of Granada by a Spanish group [25] established TOSV as one of the most important etiological agents of CNS diseases. The seropoprevalence rate for TOSV was $24.9 \%$, as also observed in Italy [48], while other seroprevalence studies carried out in northern Europe [49] report a lower rate, confirming that TOSV is endemic in the Mediterranean area. The high seroprevalence rates suggest that diagnosis is frequently missed since most cases are mild and a severe pathology appears in only a few subjects. A possible explanation could be that the TOSV circulating in this region is less neurovirulent than the Italian one, but this has been refuted by some case reports describing serious clinical manifestations in TOSV infected patients. Two unusual severe neurological sequelae were reported, and in both cases TOSV diagnosis was carried out by RT-PCR and serological methods. Immunoglobulins $\mathrm{M}$ were detected at a very late stage of infection, while a borderline level of IgG was found several months after admission. Both patients reported ischemic complications and the outcome of the infection was probably influenced by their compromised immune systems [22]. A case of deafness after TOSV meningitis has also recently been described [30]. In any case, the seasonal distribution, between June and October with a peak of incidence in August (53\%), the age dependency of TOSV infection and the predominance of disease in rural area residents $(11.64 \%$ ) are similar to those recorded in Italy [50, 51]. In 2003, the Spanish Ministry of Health sponsored "EVITAR" (Enfermedades Viricas Transmitidas por Artropodos y Roederes), a network for the surveillance of arthropod- and rodent-transmitted viruses. As a part of this study, a broad serological and molecular investigation on TOSV was performed [25]. TOSV was also isolated from sandfly pools captured in the Granada province and its genome was sequenced, providing genetic information for a better characterization of TOSV strains circulating in Spain.

\section{TOSCANA VIRUS IN FRANCE}

Toscana virus distribution is not restricted to Italy and Spain, as other European countries are also affected. During 

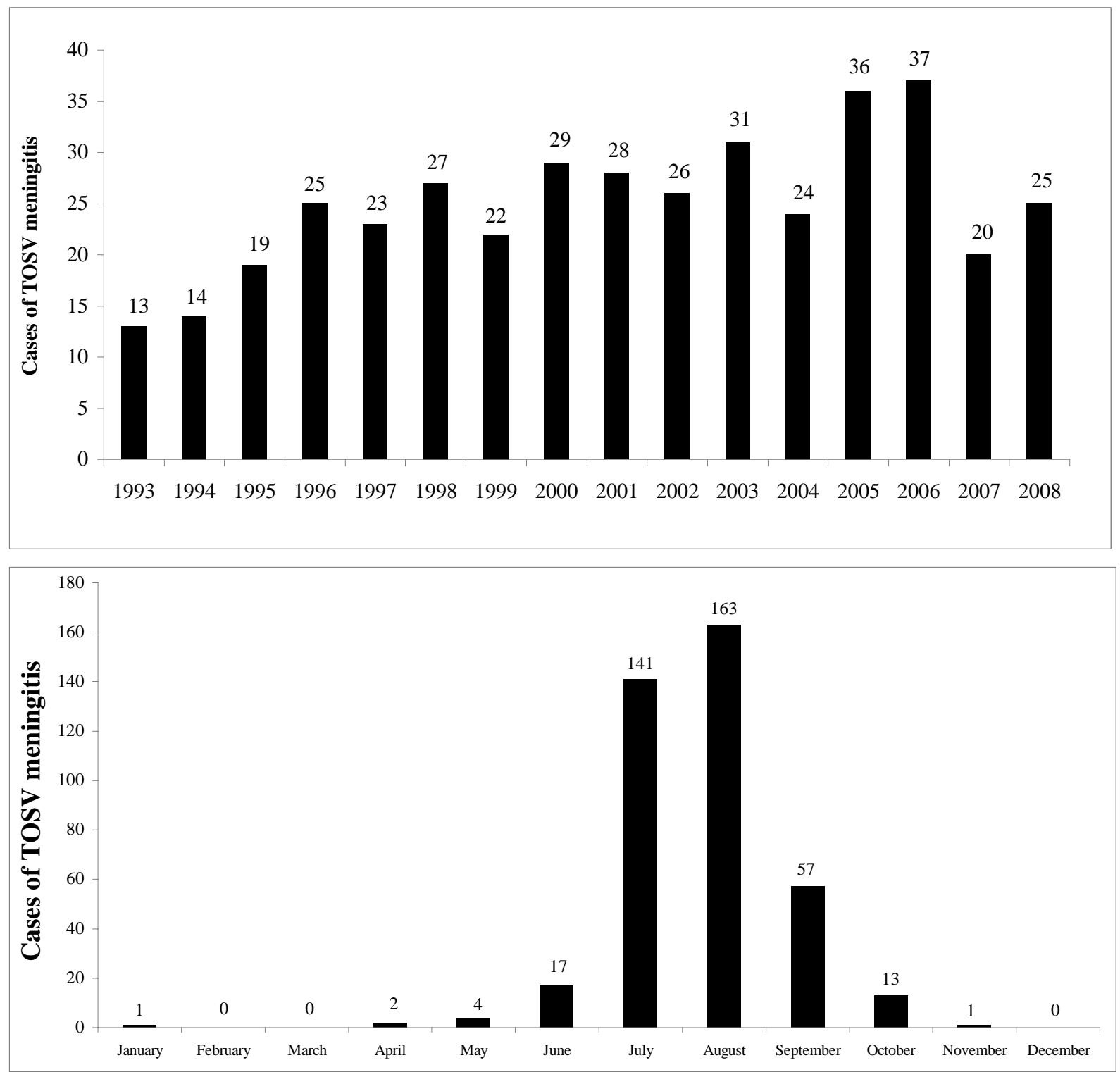

Fig. (1). (A) Toscana virus meningitis in the Siena area during the years 1993-2008. (B) Seasonal distribution of TOSV meningitis in Tuscany.

\section{Clinical manifestation of TOSV infection}

A

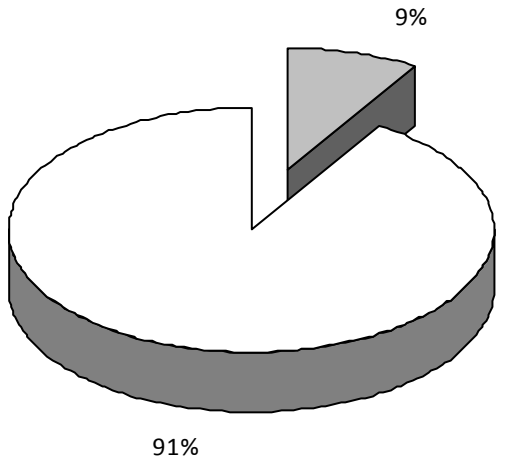

B

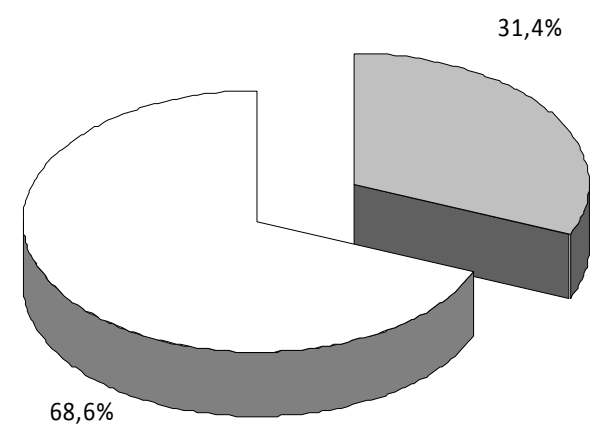

Fig. (2). Clinical manifestation of TOSV infection in seropositive subjects. Asymptomatic infection (white) is more frequent in young people (A) than in adults (B) [47]. 
a program of surveillance for West Nile virus in southern France, several samples with suspected meningitis were also tested for the presence of TOSV [26] and some resulted positive by molecular and serological techniques. The virus was then isolated on cell cultures from clinical samples and from arthropod vectors, indicating that it was circulating in southern France and could cause neurological disease in some subjects [33]. To date, two native cases of TOSV infections have been reported in the south of France [21]. So far only one case of TOSV infection has been described in a German traveler returning from France [11]. Recently the first imported case of meningoencephalitis due to TOSV in a traveler returning from Italy to France was reported [18]. An interesting study on seroprevalence was conducted in volunteer blood donors in France, showing that $12 \%$ of sera from healthy donors and $18.9 \%$ of sera from patients hospitalized for CNS infection were IgG positive for TOSV, confirming that TOSV circulates in southeastern France and that a significant proportion of healthy blood donors have a history of TOSV infection [52]. These data raise concerns about potential implications for blood donors and the risk of transmitting the virus to naïve subjects.

\section{TOSV IN THE REST OF EUROPE}

Other countries in the Mediterranean basin are affected by the presence of sandflies and, consequently, arthropodborne phleboviruses. Some sporadic seroprevalence investigations performed in Greece, Cyprus, Israel, Tunisia, Algeria and even Iran, have shown that the naïve population can be infected by Phleboviruses consisting of many serotypes [27, 53-56]. Most of these studies have recorded the presence of anti SSFV antibodies, but it is likely that a specific antibody response against TOSV could also be found. The presence of sandfly fever virus was also investigated in Bosnia and Herzegovina in a serological study of the local population. The presence of specific antiTOSV antibodies was revealed in a group of patients during 2006-2008 [16]. Since this region also appears to be affected by the virus, further serological analysis are needed for evaluating the presence of TOSV in this wide area, in order to adopt measures of prevention of the disease. The circulation of endemic viruses has been facilitated through globalization, and TOSV is a good example. In fact, TOSV infections have been reported in people visiting endemic areas (Fig. 3). The first well described case concerns Swedish soldiers based in Cyprus during 1985: twenty percent showed seroconversion to TOSV with specific IgG without any signs of illness [14]. In light of these data, a retrospective investigation was conducted by Eitrem et al. on Swedish tourists that had visited the region for the presence of Toscana virus in Cyprus [57]. All three serotypes of the sandfly fever viruses (Sicilian, Naples and Toscana) were detected in Cyprus, with a higher incidence of Sicilian and Naples strains than Toscana (antibody prevalence rates $32 \%$ and $57 \%$, respectively) [23]. Other scientists have focused their attention on this emerging virus in order to diagnose some forms of meningitis, particularly those affecting people who had visited endemic areas in the summer. In fact, several cases of aseptic meningitis in tourists returning from Italy, Spain or France were related to TOSV. Some infections imported into Germany by people returning from a vacation in Tuscany, France, Spain or Portugal have been reported [11, 12, 49, 58-61]. Another case of imported TOSV infection has been recorded in the Netherlands, where a patient with meningoencephalitis was hospitalized after a vacation in central Italy during the summer [62]. Other imported Toscana virus infections acquired by travelers have been reported during the past few years. In Switzerland, a case of meningitis due to TOSV infection was reported in a tourist who had stayed on the coast of Tuscany (Elba Island) during August [63]. On the basis of these data, Toscana virus meningitis should be included in the differential diagnosis of people with neurological symptoms returning from a holiday in the Mediterranean area.

\section{PHYLOGENETIC ANALYSIS AMONG TOSV ISO- LATES}

A number of TOSV strains have been isolated from clinical samples and Phlebotomus spp. and their genomes have been partially or fully sequenced allowing for a phylogenetic analysis among strains circulating in the Mediterranean. A comparison was carried out among the several nucleotide and aminoacid sequences available in GenBank. Few differences were found in a partial sequence of the nucleoprotein gene among strains isolated in Italy, indicating that at least four different genotypes were circulating in the same area [39]. A later and more detailed analysis of a portion of the $M$ fragment encoding the $G_{N}$ glycoprotein was performed by Venturi et al. on some Italian TOSV isolates. Phylogenetic analysis revealed four different lineages which did not show a close correspondence between viral strains and an area or a year of isolation, or with the host species. Finally, no correlation between phylogenetic clusters and the clinical presentation of the disease could be observed [34]. However, this study did not analyze the $\mathrm{G}_{\mathrm{C}}$ gene, the most variable viral gene encoding the protein, which is probably involved in recognition and binding to the cell receptor [32]. This analysis revealed a nucleotide variability in the $M$ segment among circulating strains of TOSV, without correlating any variation in the antigenic properties with a more neurovirulent strain. At this aim, different TOSV strains from Spain were compared with isolates from patients and vectors and the Italian reference strain (ISS Phl.3) [25]. Sequencing of the N gene and, partially the $\mathrm{L}$ gene, of strains isolated from patients and from vectors showed complete nucleotide and amino acid homology. The differences between TOSV and the Italian strain indicated, however, that at least two lineages of TOSV are circulating. In order to more fully clarify this finding, a phylogenetic analysis of the entire genome of TOSV strains was carried out on isolates from Spain and France by Collao et al. [31]. Pairwise comparison among the genomes showed that the $\mathrm{S}$ segment is highly conserved, in particular in the $\mathrm{N}$ gene, while the NSs coding sequence is more variable. Among the $\mathrm{L}$ and $\mathrm{M}$ genes, the $\mathrm{M}$ shows the highest rate of mutation. This suggests the presence of two geographically distinct TOSV genotypes, A and B. The TOSV A genotype includes all the Italian strains and it is also circulating in France and Portugal; the TOSV B genotype is circulating in Spain, France and Portugal. However, the virus circulation in Portugal must still be well clarified [31]. Geographic differences in genotype distribution may be related to differences in vector distribution. 


\section{Geographical circulation of TOSV in Europe}

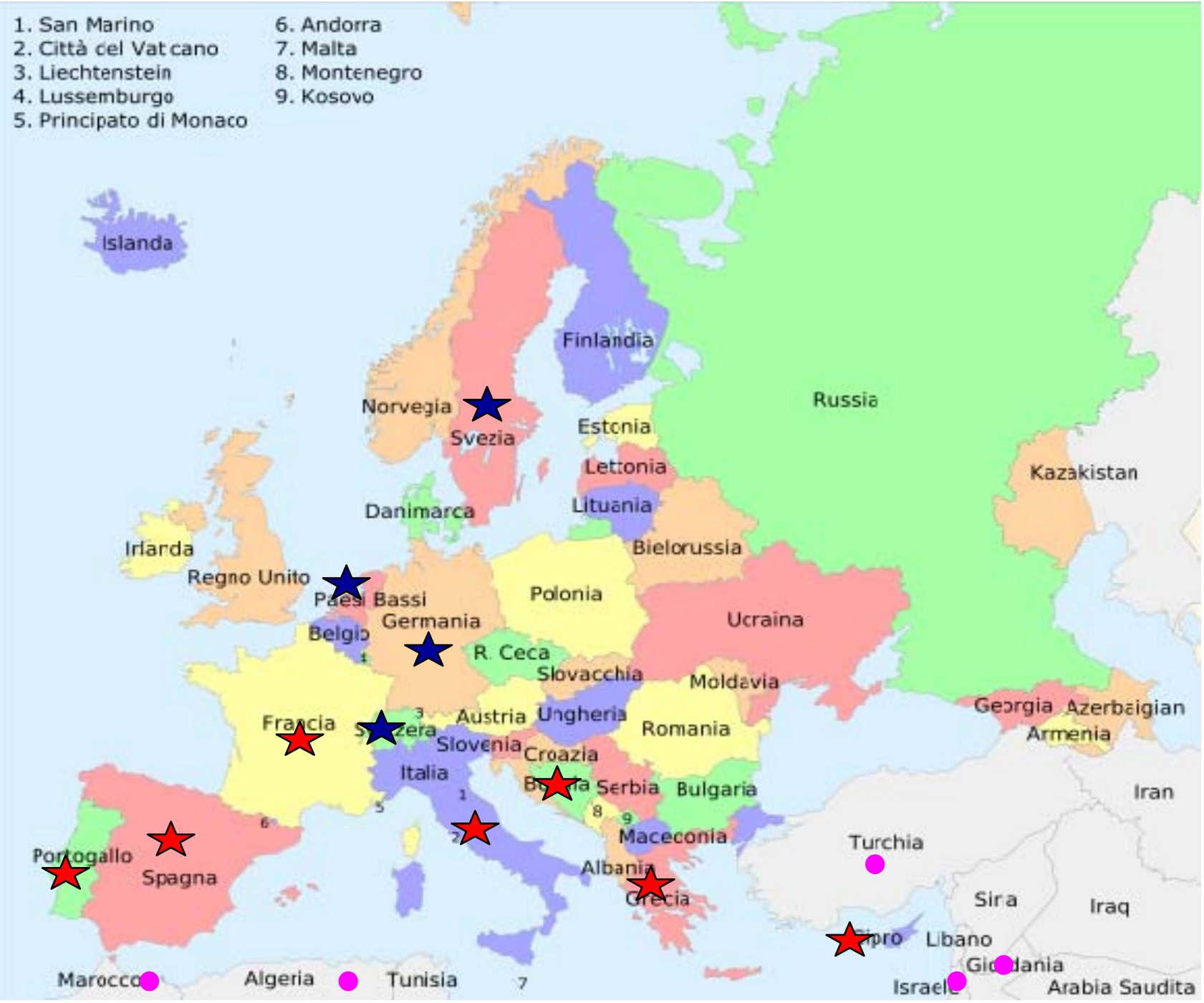

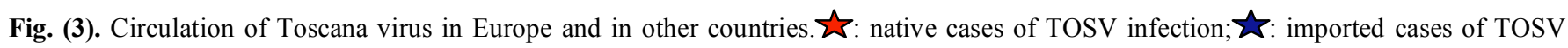
infection; - TOSV seropositivity in the population.

\section{CONCLUSION}

The study and surveillance of arbovirus infections should be considered worldwide, since they may cause emergent diseases and may represent an important public health problem in the coming years. Globalization and habitat modification have introduced new infective agents in different areas, and global air travel, deforestation, wars and changes in agricultural practices, among other factors, have changed our relationship with flora and fauna. Thus, new diseases have emerged. It is also very important to know how viruses and other pathogens evolve so that we will better be able to treat them. TOSV is an interesting example of an emergent virus transmitted by sandflies. Detailed information of the TOSV reservoir host is needed. Except for the data regarding its isolation from Pipistrellus kuhlii, no other information is available at this time. A serological study performed on some animal species in Tuscany revealed that ovines and, in particular, horses can be infected by TOSV, apparently, without symptoms [4]. However, further studies are necessary for identifying the reservoir hosts of this virus that are responsible for maintaining it. Recent cases of more serious and unusual clinical pathologies due to TOSV in humans have been described $[21,22,28-30]$, indicating that modification in host or in vector, as well as in viral agents, can represent an important factor responsible for extending the range of well-known arboviruses and the unexpected neurovirulence from a "common" pathogen. There is no treatment for TOSV infection, but supportive therapy is sometimes necessary in patients with neurological disease. Moreover, not only European countries but also others where phlebotomines are diffused should be alert to TOSV as an emergent cause of CNS infections. Only prevention, based on large epidemiological studies and research, and the development of new vaccines may be useful for controlling this viral infection. 


\section{REFERENCES}

[1] Verani P, Ciufolini MG, Nicoletti L, et al. Ecological and epidemiological studies of Toscana virus, an arbovirus isolated from Phlebotomus. Ann Ist Super Sanità 1982; 18: 397-9.

[2] Verani P, Nicoletti L, Ciufolini MG. Antigenic and biological characterization of Toscana virus, a new Phlebotomus fever group virus isolated in Italy. Acta Virol 1984; 28: 39-47.

[3] Ciufolini MG, Maroli M, Verani P. Growth of two phleboviruses after experimental infection of their suspected sand fly vector, Phlebotomus perniciosus (Diptera: Psychodidae). Am J Trop Med Hyg 1985; 34: 174-9.

[4] Ciluna MT, Scaramozzino P, Cocumelli C, Cusi MG, Perfetti G, Autorino GL. Preliminary observations on the potential role of some mammalian reservoirs of Toscana virus. International Meeting on Emerging Diseases and Surveillance 2007 February 2325, Vienna, Austria, 2005

[5] Accardi L, Grò MC, Di Bonito $\mathrm{P}$, et al. Toscana virus genomic L segment: molecular cloning, coding strategy and amino acid sequence in comparison with other negative strand RNA viruses. Virus Res 1993; 27: 119-31.

[6] Di Bonito P, Mochi S, Grò MC, et al. Organization of the M genomic segment of Toscana phlebovirus. J Gen Virol 1997; 78: 77-81

[7] Grò MC, Di Bonito P, Fortini D, et al. Completion of molecular characterization of Toscana phlebovirus genome: nucleotide sequence, coding strategy of $\mathrm{M}$ genomic segment and its amino acid sequence comparison to other phleboviruses. Virus Res 1997; 51: 81-91.

[8] Giorgi C, Accardi L, Nicoletti L, et al. Sequences and coding strategies of the S RNAs of Toscana and Rift Valley fever viruses compared to those of Punta Toro, Sicilian Sandfly fever, and Uukuniemi viruses. Virology 1991; 180: 738-53.

[9] Calisher $\mathrm{CH}$, Weinberg AN, Muth DJ, et al. Toscana virus infection in United States citizen returning from Italy. Lancet 1987; 1: $165-6$.

[10] Charrel RN, Gallian P, Navarro-Mari JM, et al. Emergence of Toscana virus in Europe. Emerg Infect Dis 2005; 11: 1657-63.

[11] Dobler G, Treib J, Haass A, et al. Toscana virus infection in German travellers returning from the Mediterranean. Infection 1997; 25: 325.

[12] Ehrnst A, Peters CJ, Niklasson B, Svedmyr A, Holmgren B. Neurovirulent Toscana virus (a sandfly fever virus) in Swedish man after visit to Portugal. Lancet 1985; 1: 1212-3.

[13] Eitrem R, Niklasson B, Weiland O. Sandfly fever among Swedish tourists. Scand J Infect Dis 1991; 23: 451-7.

[14] Eitrem R, Vene S, Niklasson B. Incidence of sand fly fever among Swedish United Nations soldiers on Cyprus during 1985. Am J Trop Med Hyg 1990; 43: 207-11.

[15] Endris RG, Perkins PV. Transmission of Toscana virus by sandflies in Italy. Lancet 1987; 1: 808-9.

[16] Hukić M, Salimović-Besić I. Sandfly - Pappataci fever in Bosnia and Herzegovina: the new-old disease. Bosn J Basic Med Sci 2009; 9: 39-43.

[17] Sonderegger B, Hachler H, Dobler G, Frei M. Imported aseptic meningitis due to Toscana virus acquired on the island of Elba, Italy, August 2008. Euro Surveill 2009; 14. pii: 19079.

[18] Epelboin L, Hausfater P, Schuffenecker I, et al. Meningoencephalitis due to Toscana virus in a French traveler returning from central Italy. J Travel Med 2008; 15: 361-3.

[19] Verani P, Nicoletti L, Ciufolini MG, Balducci M. Viruses transmitted by sandflies in Italy. Parassitologia 1991; 33: 513-8.

[20] Braito A, Ciufolini MG, Pippi L, et al. Phlebotomus-transmitted Toscana virus infections of the central nervous system: a sevenyear experience in Tuscany. Scand J Infect Dis 1998; 30: 505-8.

[21] Hemmersbach-Miller M, Parola P, Charrel RN, Paul Durand J, Brouqui P. Sandfly fever due to Toscana virus: an emerging infection in southern France. Eur J Intern Med 2004; 15: 316-317.

[22] Sanbonmatsu-Gámez S, Pérez-Ruiz M, Palop-Borrás B, NavarroMarí JM. Unusual manifestation of Toscana virus infection, Spain. Emerg Infect Dis 2009;15:347-8.

[23] Eitrem RM. Stylianou, B. Niklasson. High prevalence rates of antibody to three sandfly fever viruses(Sicilian, Naples and Toscana) among Cypriots. Epidemiol Infect 1991; 107: 685-691.

[24] Santos L, Simões J, Costa R, Martins S, Lecour H. Toscana virus meningitis in Portugal, 2002-2005. Euro Surveill 2007; 12: e3-4.
[25] Sanbonmatsu-Gámez S, Pérez-Ruiz M, Collao X, et al. Toscana virus in Spain. Emerg Infect Dis 2005; 11: 1701-7.

[26] Peyrefitte CN, Devetakov I, Pastorino B, et al. Toscana virus and acute meningitis, France. Emerg Infect Dis 2005; 11: 778-80.

[27] Papa A, Konstantinou G, Pavlidou V, Antoniadis A. Sandfly fever virus outbreak in Cyprus. Clin Microbiol Infect 2006; 12: 192-4.

[28] Portolani M, Sabbatini AM, Beretti F, et al. Symptomatic infections by Toscana virus in the Modena province in the triennium 1999-2001. New Microbiol 2002; 25: 485-8.

[29] Baldelli F, Ciufolini MG, Francisci D, et al. Unusual presentation of life-threatening Toscana virus meningoencephalitis. Clin Infect Dis 2004; $38: 515-20$

[30] Martínez-García FA, Moreno-Docón A, Segovia-Hernández M, Fernández-Barreiro A. Deafness as a sequela of Toscana virus meningitis. Med Clin (Barc) 2008; 130: 639.

[31] Collao X, Palacios G, Sanbonmatsu-Gámez S, et al. Genetic diversity of Toscana virus. Emerg Infect Dis 2009; 15: 574-7.

[32] Valentini M, Valassina M, Savellini GG, Cusi MG. Nucleotide variability of Toscana virus $M$ segment in strains isolated from clinical cases. Virus Res 2008; 135: 187-90.

[33] Charrel RN, Izri A, Temmam S, et al. Cocirculation of 2 genotypes of Toscana virus, southeastern France. Emerg Infect Dis 2007; 13 465-8.

[34] Venturi G, Ciccozzi M, Montieri S, et al. Genetic variability of the $\mathrm{M}$ genome segment of clinical and environmental Toscana virus strains. J Gen Virol 2007; 88: 1288-94.

[35] Verani P, Ciufolini MG, Caciolli S, et al. Ecology of viruses isolated from sand flies in Italy and characterized of a new Phlebovirus (Arabia virus). Am J Trop Med Hyg 1988; 38: 433-9.

[36] Verani P, Nicoletti L, Ciufolini MG. Antigenic and biological characterization of Toscana virus, a new Phlebotomus fever group virus isolated in Italy. Acta Virol 1984a; 28: 39-47.

[37] Nicoletti L, Verani P, Caciolli S, et al. Central nervous system involvement during infection by Phlebovirus toscana of residents in natural foci in central Italy (1977-1988). Am J Trop Med Hyg 1991; 45: 429-34.

[38] Valassina M, Meacci F, Valensin PE, Cusi MG. Detection of neurotropic viruses circulating in Tuscany: the incisive role of Toscana virus. J Med Virol 2000; 60: 86-90.

[39] Valassina M, Cuppone AM, Bianchi S, Santini L, Cusi MG. Evidence of Toscana virus variants circulating in Tuscany, Italy, during the summers of 1995 to 1997. J Clin Microbiol 1998; 36: 2103-4.

[40] Valassina M, Valentini M, Pugliese A, Valensin PE, Cusi MG. Serological survey of toscana virus infections in a high-risk population in Italy. Clin Diagn Lab Immunol 2003; 10: 483-4.

[41] Braito A, Corbisiero R, Corradini S, et al. Evidence of Toscana virus infections without central nervous system involvement: a serological study. Eur J Epidemiol 1997; 13: 761-4.

[42] Cusi MG. Toscana virus from Italy to beyond. ECCMID; May 1619; Helsinki, Finland; 2009.

[43] Pugliese A, Beltramo T, Torre D. Emerging and re-emerging viral infections in Europe. Cell Biochem Funct 2007; 25: 1-13.

[44] Francisci D, Papili R, Camanni G et al. Evidence of Toscana virus circulation in Umbria: first report. Eur J Epidemiol 2003; 18: 457 9.

[45] Di Nicuolo G, Pagliano P, Battisti S, et al. Toscana virus central nervous system infections in southern Italy. J Clin Microbiol 2005; 43: 6186-8.

[46] Venturi G, Madeddu G, Rezza G, et al. Detection of Toscana virus central nervous system infections in Sardinia Island, Italy. J Clin Virol 2007; 40: 90-1.

[47] Terrosi C, Olivieri R, Bianco C, Cellesi C, Cusi MG. Agedependent seroprevalence of Toscana virus in central Italy and correlation with the clinical profile. Clin Vaccine Immunol 2009; 16: $1251-2$

[48] D'Ovidio MC, Venturi G, Fiorentini C, et al. Occupational risk associated with Toscana virus infection in Tuscany, Italy. Occup Med (Lond) 2008; 58: 540-4.

[49] Schwarz TF, Jäger G, Gilch S, Pauli C. Serosurvey and laboratory diagnosis of imported sandfly fever virus, serotype Toscana, infection in Germany. Epidemiol Infect 1995; 114: 501-10.

[50] Navarro JM, Fernández-Roldán C, Pérez-Ruiz M, Sanbonmatsu S, de la Rosa M, Sánchez-Seco MP. Meningitis by Toscana virus in Spain: description of 17 cases. Med Clin (Barc) 2004; 122: 420-2. 
[51] Echevarria, JM, De Ory F, Guisasola ME, et al. Acute meningitis due to Toscana virus infection among patients from both the Spanish Mediterranean region and the region of Madrid. J Clin Virol 2003; 26: 79-84.

[52] De Lamballerie X, Tolou H, Durand JP, Charrel RN. Prevalence of Toscana virus antibodies in volunteer blood donors and patients with central nervous system infections in southeastern France. Vector Borne Zoonotic Dis 2007; 7: 275-7.

[53] Cohen D, Zaide Y, Karasenty E, et al. Prevalence of antibodies to West Nile fever, sandfly fever Sicilian, and sandfly fever Naples viruses in healthy adults in Israel. Public Health Rev 1999; 27: 21730.

[54] Chastel C, Bach-Hamba D, Launay H, Le Lay G, Hellal H, Beaucournu JC. Arbovirus infections in Tunisia: new serological survey of small wild mammals. Bull Soc Pathol Exot Filiales 1983; 76: $21-33$.

[55] Tavana AM. The seroepidemiological studies of Sand fly fever in Iran during imposed war. Iranian J Publ Health 2001; 30: 145-146.

[56] Izri A, Temmam S, Moureau G, Hamrioui B, de Lamballerie X, Charrel RN. Sandfly fever Sicilian virus, Algeria. Emerg Infect Dis 2008; 14: 795-7.
$[57]$

[60] Defuentes G, Rapp C, Imbert P, Durand JP, Debord T. Acute meningitis owing to phlebotomus fever Toscana virus imported to France. J Travel Med 2005; 12: 295-6.

[61] Schwarz TF, Jäger G, Gilch S, et al. Travel-related vector-borne virus infections in Germany. Arch Virol Suppl 1996; 11: 57-65.

[62] Beersma MF, Grimbergen YA, Kroon FP, Veldkamp PJ. Meningitis caused by Toscana virus during a summer stay in Italy. Ned Tijdschr Geneeskd 2004; 148: 286-8.

[63] Sonderegger B, Hachler H, Dobler G, Frei M. Imported aseptic meningitis due to Toscana virus acquired on the island of Elba, Italy, August 2008. Euro Surveill 2009; 14: 19079.

This is an open access article licensed under the terms of the Creative Commons Attribution Non-Commercial License (http: //creativecommons.org/licenses/by-nc/ 3.0/) which permits unrestricted, non-commercial use, distribution and reproduction in any medium, provided the work is properly cited. 